\begin{tabular}{|l|l|l|}
\hline \multicolumn{2}{|c|}{ PublisherInfo } \\
\hline \hline PublisherName & $:$ & BioMed Central \\
\hline \hline PublisherLocation & $:$ & London \\
\hline \hline PublisherImprintName & $:$ & BioMed Central \\
\hline \hline
\end{tabular}

\title{
Missing cancers at prevalence screen affects their size at incidence screen
}

\begin{tabular}{|l|l|l||}
\hline \multicolumn{2}{|c||}{ ArticleInfo } \\
\hline \hline ArticleID & $:$ & 3614 \\
\hline \hline ArticleDOI & $:$ & $10.1186 /$ bcr-1999-66592 \\
\hline \hline ArticleCitationID & $:$ & 66592 \\
\hline \hline ArticleSequenceNumber & $:$ & 34 \\
\hline \hline ArticleCategory & $:$ & Paper Report \\
\hline \hline ArticleFirstPage & $:$ & 1 \\
\hline \hline ArticleLastPage & $:$ & 4 \\
\hline \hline & & RegistrationDate : 1999-7-19 \\
\hline ArticleHistory & $:$ & OnlineDate \\
\hline \hline ArticleCopyright & $:$ & Current Science Ltd1999-7-19 \\
\hline \hline ArticleGrants & $:$ & \\
\hline \hline ArticleContext & $:$ & 1305811 \\
\hline \hline
\end{tabular}




\section{Keywords}

breast cancer, false negative, incidence screen, mammography, tumour size

\section{Introduction}

Cancer detection rate is an important measure of screening performance. If cancers are missed at prevalence screen, and fail to present as interval cancers before the next screen is due, then their detection at incidence screen may artificially boost the detection rate at that screen. Such cancers might be expected to be larger than those detected at incidence screen but not present at prevalence screen.

\section{Aims}

To investigate the effect of failing to detect cancers at prevalence screen on the relative distribution of small $(<15 \mathrm{~mm})$ and large (or $>15 \mathrm{~mm})$ cancers detected at the first incidence screen.

\section{Comments}

Since missing around one-third of cancers at prevalence screen had little effect on the size distribution of cancers detected at incidence screen, this study highlights the importance of examining cancers in the whole invited population when evaluating screening performance. The author points out that the aggressive tumours which would most benefit from early detection are most likely to appear as intervals, thus are under-represented amongst the false negatives from the prevalence screen. These results also emphasise the need to identify the early mammographic signs of poor prognosis such that efforts can be made to ensure the prompt detection of aggressive cancers.

\section{Methods}


Full pathology and prevalence screening films were available for 103 of 116 cancers that were detected at first incidence screen within the Bolton, Bury and Rochdale breast screening programme between 1990-1998. Cancers detected at early recall were excluded. One radiologist reviewed the prevalence round screening films without access to the incidence round films and without knowledge of the site and side of the cancer. Cases were classified as true interval if no significant abnormality was perceived at the site of the subsequent cancer. They were classified as false negative if an abnormality sufficient to warrant assessment was perceived at the site subsequently demonstrated to correspond to that of the cancer. Classifications were confirmed with reference to incidence round films. Tumour type, size and grade were recorded.

\section{Results}

Of 103 cases, 32 (31\%) were classified as false negative; 21 of 54 (39\%) first screened before April 1992 and 11 of 49 (22\%) first screened after April 1992. Around half of all incidence screen cancers measured $<15 \mathrm{~mm}$ regardless of tumour type, including $12(38 \%)$ of the 32 false negatives. Amongst the false negatives, there seemed to be an excess of lobular cases (of 8 lobular cancers, 6 were classified as false negative) and a dearth of grade 3 ductals ( 5 false negative of 28 total).

\section{Discussion}

Previous studies have reported false negative rates of $13-26 \%$ for prevalence screen. However the method of review and classification varies. In this study the false negative rate decreased after April 1992 , corresponding with the national improvement in programme performance. The fact that $38 \%$ of false negative cancers measured $<15 \mathrm{~mm}$ at incidence screen was not unexpected since many of the more aggressive cancers (eg grade 3 ductals) will have presented symptomatically as intervals rather than remaining to be detected at incidence screen. The high proportion of lobular cases classified as false negatives is consistent with their non-specific mammographic appearance. The target for the UK programme is to detect at least $50 \%$ of all cancers measuring $<15 \mathrm{~mm}$. Had there been no false negatives at prevalence screen, the rate of detection at $<15 \mathrm{~mm}$ for incidence screen cancers would have risen from $49.5 \%$ to $54.9 \%$. Thus the proportion (but not absolute number) of small cancers detected at incidence screen is little influenced by performance at the preceding screen. 


\section{References}

1. Pandha HS, Martin LA, Rigg A, Hurst HC, Stamp GW, Sikora K, Lemoine NR: Breast cancer missed in the prevalent screening round: effect upon the size distribution of incident round detected cancers. J Med Screen. 1999, 6: 28-29. 